doi https://doi.org/10.29327/224874.3.1-8

\title{
diálogos entre o ensino de idiomas \\ e de artes no contexto do projeto espanglish
}

${ }^{1}$ Márcia S.V., ${ }^{2}$ Roberto L.S., ${ }^{3}$ Graziani F.C.A.

1 instituto federal de educação, ciência e tecnologia do tocantins

2 instituto federal de educação, ciência e tecnologia do tocantins

3 instituto federal de educação, ciência e tecnologia do tocantins

•e-mail de contato principal: marcia.vale@ifto.edu.br

resumo

este estudo busca compreender o potencial da metodologia colaborativa como uma estratégia de ensino-aprendizagem dialógica e suas implicações para o ensino de idiomas e de arte. Trata-se de uma pesquisa qualitativa, tendo como contexto de investigação o Projeto Espanglish e como sujeitos investigados estudantes que cursam o ensino médio. Adotamos como referencial teórico os estudos de Bakhtin, de Freire e de outros autores na área da Educação Colaborativa. Os resultados apontam a potencialidade dessa metodologia em possibilitar o intercâmbio de saberes, a compreensão de outras culturas e a promoção do ensino-aprendizagem aberto ao mundo e a diversidade.

palavras-chave: educação colaborativa, dialogismo, arte, língua estrangeira.

\section{como citar este artigo}

Vale, M. S., Sales, R. L. \& Anicézio, G. F. C. (2021). Diálogos entre o ensino de idiomas e de artes no contexto do projeto espanglish. Revista Interdisciplinar em Estudos de Linguagem, 3(1), 3-11, doi https://doi.org/10.29327/224874.3.1-8 


\section{introdução}

Ao nos debruçarmos com o ensino de língua estrangeira na educação básica, sobretudo no ensino médio, percebemos que ele vem sendo alvo de várias discussões e pesquisas que buscam apresentar metodologias eficazes que culminem com as finalidades desse ensino, propostos pelas diretrizes dos documentos oficias da educação, a saber: "participação mais plena dos jovens nas diferentes práticas socioculturais que envolvem o uso das linguagens" (BNCC, 2018, p. 481).

Nessa perspectiva, o presente trabalho busca compreender e explorar o potencial da metodologia colaborativa como uma estratégia de ensino-aprendizagem dialógica e suas implicações para o processo de ensino de idiomas e de arte, para tanto, iniciamos a escrita com a definição da educação colaborativa no campo teórico, seguida de uma reflexão sobre as práticas inovadoras de educação colaborativa numa perspectiva autônoma, problematizadora e dialógica para o ensino de língua estrangeira e artes, destarte, explanamos sobre o projeto Espanglish e suas finalidades e apresentamos a metodologia desenvolvida nas oficinas de criação, fazendo um recorte para a análise dos dados discutidos na seção dos Resultados.

Utilizamos a pesquisa qualitativa, adotando o estudo de caso como técnica de análise Gil (2008). Os dados coletados foram extraídos dos registros em diários de campo, de depoimentos, de rodas de conversas, de filmagens e de fotografias. Em respeito às questões éticas e ao anonimato dos adolescentes/jovens e dos demais professores envolvidos no estudo, optamos em identificá-los com nomes fictícios e/ou símbolos gráficos.

O artigo se fundamenta nos estudos de Paulo Freire (1996, 2011a, 2011b), em especial a perspectiva do diálogo problematizador; nos estudos de Mikhail Bakhtin (2009, 2011), com destaque para sua perspectiva em relação ao dialogismo; e em autores que estudam a Educação Colaborativa (Aparici \& Acedo, 2010; Bagetti, 2015; Brant, 2008; Damiani, 2012; Figueiredo, 2006; Lima \& Pinho, 2007; Torres, 2004).

\section{educação colaborativa}

Em seus estudos, Damiani (2008) afirma que um trabalho colaborativo pode ser definido como um espaço para a promoção de ações conjuntas, onde os membros de um grupo, "ao trabalharem juntos, se apoiam, visando atingir objetivos comuns negociados pelo coletivo, estabelecendo relações que tendem à nãohierarquização, liderança compartilhada, confiança mútua e co-responsabilidade pela condução das ações" (p. 215). A autora enfatiza que o trabalho colaborativo também pode resgatar valores como as relações de igualdade e a solidariedade, que foram se perdendo ao longo de uma dinâmica social cada vez mais competitiva e individualista.

De forma mais específica, os estudos de Torres (2004) e Bagetti (2015) apontam como as diversas concepções científicas em relação ao conceito de educação colaborativa convergem para o sentido de uma "construção coletiva do conhecimento, que emerge da troca entre pares, das atividades práticas dos alunos, de suas reflexões, de seus debates e questionamentos" (Torres, 2004, p. 50), interação entre os envolvidos, flexibilização dos papéis dos autores e de suas relações. Esses estudos também destacam como as estratégias de colaboração potencializam as produções de conhecimento por meio da autoria coletiva, da promoção da autonomia dos estudantes, da valorização da liberdade com responsabilidade e da interação com o grupo.

Esses benefícios também são destacados nos estudos de Aparici \& Acedo (2010, p. 141), os quais enfatizam cinco elementos que caracterizam a aprendizagem colaborativa: 1 - responsabilidade individual (todos os integrantes assumem a responsabilidade pelo desenvolvimento individual dentro do grupo); 2 interdependência positiva (os membros do grupo criam laços e positiva dependência uns dos outros para atingir o objetivo comum); 3 habilidades colaborativas (são habilidades essenciais ao sucesso do trabalho em equipe, a liderança e gerenciamento de conflitos); 4 - interação promotora (a interação entre os integrantes desenvolve relações interpessoais e estabelece estratégias 
efetivas de aprendizagem); 5 - processo de grupo (em encontros periódicos o grupo avalia as produções, desempenho e funcionamento, realizando aprimoramentos necessários).

Pretto (2013, p. 310) afirma que é relevante a troca entre os produtos culturais, e essa nova produção e diálogo permanente com o instituído, produz novos produtos, novas culturas e novos conhecimentos. Assim, a educação deve romper com o paradigma de competição e aprisionamento do conhecimento e reforçar a educação para liberdade do saber (Brant, 2008, p. 69). Para tanto, deve-se propor uma ação educativa viável, de forma transversal que busque alternativas de formação com o foco na criticidade do sujeito.

\section{educação colaborativa, dialogismo e o diálogo problematizador}

Freire (1996, 2011a, 2011b) propõe a educação como prática da liberdade, seus estudos são construídos numa perspectiva libertadora, voltada para a valorização dos saberes individuais e coletivos em diálogo com a realidade social. Nessa ótica, o autor reforça a necessidade do exercício da cooperação, compartilhamento e autonomia no processo ensino-aprendizagem. Para ele, "ensinar não é transmitir conhecimento, mas permitir que o educando construa seu próprio saber. Essa é a tarefa do educador" (Freire, 1996, p. 47).

Trata-se, pois, da educação para o diálogo que se faz impactante para os envolvidos, assim, é essencial que seja mediada de forma problematizadora. É importante salientar que problematizar é exercer uma análise crítica sobre a realidadeproblema. Freire defende que ser um sujeito crítico, autônomo e livre "implica a negação do homem abstrato, isolado, solto, desligado do mundo, assim também como a negação do mundo como uma realidade ausente dos homens" (Freire, 2011b, p. 98).

Logo, para Freire, a educação deve ser dialógica e problematizadora para que se tenha significado e, assim promova condições para a educação emancipatória, crítica e libertadora na qual os sujeitos possam ter condições de fazer uma leitura crítica do mundo e que consigam se sobressair frente aos desafios cotidianos.
O diálogo, conforme Bakhtin (2009, 2011), é uma ponte que conecta o eu ao outro, constituindo e formando o "ser", ao mesmo tempo em que influencia e é influenciado pela linguagem. Assim, a realidade concreta se apresenta na interação entre o "eu" e o "outro" por meio da língua e da interação verbal via enunciado. Nessa relação ocorre o diálogo entre múltiplos e diferentes valores, sentidos e visões de mundo, caracterizando, dessa forma, o debate de ideias em meio a conexão com as palavras dos diferentes emissores que participam de um mesmo discurso.

É nesse embasamento que Bakhtin (2009, 2011) constrói sua perspectiva sociointeracionista, fundamentada na concepção de que a linguagem é um fenômeno social de interação verbal, alicerçada no diálogo. Dessa forma, percebemos a educação como um espaço de interação dialógica e problematizadora, a qual promove situações de diálogo, de cooperação, de criticidade e de autonomia, condutas essas que são alicerçadas na língua viva como prática social, legitimando assim ações inovadoras que buscam ressignificar o ensino e a aprendizagem em todos os seus contextos.

\section{o projeto espanglish}

"Contextualizar o conteúdo que se quer aprender significa, em primeiro lugar, assumir que todo conhecimento envolve uma relação entre sujeito e objeto" (Brasil, 2013, p.78). O projeto Espanglish busca o ensinoaprendizagem de línguas a partir da realidade do "eu", aluno e o "outro", estrangeiro. O projeto surgiu como uma forma de ensinar as Línguas Estrangeiras, inglês e espanhol interligando o lúdico, a interdisciplinaridade e a arte. Iniciado em 2011, como uma Feira de Língua Espanhola, só passou a integrar a língua Inglesa em 2012, quando foi renomeado para Espanglish.

O projeto perpassa diversas disciplinas, como artes, história, geografia e sociologia, além das tecnologias. "O ensino por disciplina, fragmentado e dividido, impede a capacidade natural que o espírito tem de contextualizar. E é essa capacidade que deve ser estimulada e desenvolvida pelo ensino, a de ligar as partes ao todo e o todo às partes" (Morin, 2008, p. 3). 
A Espanglish busca propiciar um aprendizado significativo, pois uma língua estrangeira se aprende também conhecendo o território, as culturas e tradições de outros povos,

ação integradora capaz de suscitar comportamentos e atitudes comprometidas com princípios orientados para o respeito ao outro, às diferenças, à diversidade cultural que caracteriza todo o processo de ensino/ aprendizagem de línguas, seja de línguas ou de qualquer outro conteúdo escolar. É o esforço para a promoção da interação, da integração e cooperação entre os indivíduos de diferentes mundos culturais. É o esforço para se partilhar as experiências, antigas e novas, de modo a construir novos significados (Santos, 2004, p. 154).

O trabalho começa com a escolha $e$ sorteio de países que têm o inglês ou o espanhol como línguas oficiais, um para cada turma, seguido por pesquisas que visam conhecer e explorar o país contemplado no sorteio, momento em que também recebem orientações dos professores das diversas disciplinas. Passa-se então para o momento de interação entre os estudantes para discussão dos temas, organização da feira e seleção do conteúdo, bem como, para os ensaios de danças, teatro e preparação das comidas típicas feitas como teste, produção de cenário e figurino. E finalizado com a feira, que é a mostra de todas as pesquisas, ensaios e experimentos, apresentados em dois momentos: no palco, onde são apresentados os dados dos países e as danças típicas e na barraca, decorada de acordo com a cultura do país representado, é servido comida e bebida típica para degustação, são realizadas as apresentações dos conteúdos estudados, além de buscar a interação do público com jogos e brincadeiras.

O projeto mostra que o conhecimento é construído a partir do diálogo e da interação, pois depende do compartilhamento das informações que os alunos encontraram, da organização e apresentação delas em sala de aula para, só então, ser transmitido na culminância da feira.

\section{as oficinas de produção}

Em junho de 2018, após o sorteio dos países que iriam ser representados na $\mathrm{VI}$ edição do Projeto Espanglish e, com a meta de envolver os grupos de estudantes em um processo de construção colaborativa de espetáculos cênicos, promovemos oficinas de produção artística, organizadas nas seguintes etapas: 1. Capacitação dos estudantes para trabalhar com a metodologia colaborativa, envolvendo a orientação e a reflexão para a promoção dos diálogos entre os membros do grupo, sensibilizando-os quanto a importância de se realizar um trabalho artístico colaborativo e comunicativo-dialógico, primando pelo respeito ao outro, pela troca de saberes e experiências, pela autonomia e pela flexibilização de lideranças; 2 . Capacitação em Artes Cênicas, procurando introduzi-los nos estudos e nas práticas dessa arte, partindo de experimentos artísticos capazes de familiarizá-los com os elementos da linguagem cênica; 3 . Os estudantes foram orientados quanto às técnicas de pesquisas a serem usadas e quanto a forma de realizar a sistematização do material coletado; 4. Envolvimento dos estudantes nos trabalhos de produção coletiva de ideias, nos debates para o estabelecimento das estratégias de aprendizagem, produção do roteiro e dos materiais cênicos para o espetáculo; 5 . Leitura crítica e ressignificação do roteiro do espetáculo e do material cênico préelaborado, ensaios das cenas para a apresentação e finalização dos figurinos e cenários; 6. Conclusão do trabalho, apresentação do espetáculo e análise da experiência educacional e colaborativa do projeto.

Diante da ampla quantidade de estudantes envolvidos nas oficinas e, dos conteúdos e práticas que foram desenvolvidos, optamos em fazer um recorte, abordando a turma de estudantes da $2^{\text {a Série }}$ do Curso Médio Integrado em Agroindústria, selecionada para apresentar o país Cuba, como meio de analisar a metodologia colaborativa no ensino-aprendizagem da língua espanhola e da arte.

As etapas de trabalhos das oficinas foram organizadas e distribuídas em 4 (quatro) encontros semanais (terça, quinta, sexta e sábado), com 03 horas de duração, ocorridos no período de 02 a 30 de agosto de 2018, desenvolvidos, em sua maioria, em Língua Espanhola.

Os alunos receberam, inicialmente, uma capacitação que procurou inseri-los no universo do teatro por meio de estudos 
teórico-práticos, compreendendo as etapas de exercícios de improvisações que exploraram as expressões vocais e corporais e, a aplicação de jogos teatrais que exploraram os conceitos e princípios da dramaturgia, da interpretação, da sonoplastia, da cenografia e do figurino. Ainda nessa fase, os estudantes começaram a explorar a temática do espetáculo, pesquisando e coletando informações sobre a cultura e a história de Cuba e as aplicaram como tema e conteúdo de grande parte dos exercícios teatrais. Aos poucos, as experimentações individuais e, em grupo, foram gerando ideias-base para a produção do roteiro e do material cênico.

Decorrido esse processo, a turma foi dividida em subgrupos, conforme as funções e competências artísticas exigidas para a produção de um espetáculo cênico. Desse modo, esses subgrupos foram intitulados "grupos criativos", e distribuídos nas seguintes funções: direção, dramaturgia, interpretação, sonoplastia, figurino e cenário. Posteriormente, cada grupo criativo recebeu um líder, cuja missão era representar os interesses do seu grupo, partindo de um modo de liderar capaz de romper com as hierarquias rígidas, adotando, para isso, um modo de liderança compartilhada e baseada na colaboração, no diálogo e na negociação de ideias.

Os professores orientadores atuaram como moderadores e gestores do processo de aprendizagem, estimulando e capacitando os estudantes a desenvolver um pensamento crítico em meio ao processo de negociação, de diálogo e de construção colaborativa do conhecimento.

Esses foram os primeiros passos dados pelos coordenadores do projeto, pelos professores orientadores e pela turma de estudantes, para organizar, estruturar e realizar as oficinas colaborativas de produção cênica, que gerou como obra artística, o espetáculo "El Mundo de Cuba".

\section{resultados e discussões}

A fase de criação do espetáculo se iniciou com a produção do roteiro da peça teatral que ocorreu em forma de autoria coletiva. Ao longo das rodas de conversas os estudantes foram provocados a descobrir a verdadeira história de Cuba, tendo em vista que muitos manifestaram opiniões depreciativas sobre a cultura cubana e o seu povo. Nesse sentido, os professores orientadores realizaram um trabalho de redirecionamento dos estudantes, provocando-os a refletirem sobre sua cultura local confrontando-a com a cubana. Os estudantes também foram provocados a reavaliarem seus conceitos e a realizarem novos estudos sobre Cuba com um olhar mais crítico e mais sensível aos valores e diferenças culturais. Diante desse desafio, os estudantes realizaram novas pesquisas em materiais e documentos que mostraram a realidade cubana por trás da visão estereotipada propagada por grande parte dos meios de comunicação de massa. E assim, a medida que as pesquisas dos estudantes avançavam, seus discursos foram entrando em confronto com os discursos midiáticos.

Nessa perspectiva, nasceu o textoroteiro, tecido por todas as mãos dos grupos criativos, escrito no idioma espanhol. O texto conta a história de um casal de namorados que convida um grupo de brasileiros para conhecer Cuba e grande parte do seu contexto histórico-cultural. As vozes do casal norteiam imagens, poesias, músicas, diálogos com outros personagens e movimentos de dança que procuraram expressar, de forma didática e lúdica, as belezas e as riquezas culturais e históricas do país Cuba. Esse espetáculo foi premiado como melhor apresentação artística do evento Espanglish, edição 2018, na categoria idioma espanhol.

Diante dessas produções, observamos que cada estudante interagiu na construção colaborativa do texto-roteiro, estimulando o intercâmbio de ideias e contribuindo com as informações, baseadas em obras de diferentes formatos (texto, som, vídeo e imagem). Para essa produção, os estudantes dialogaram e exploraram os conteúdo de Cuba disponíveis em obras e plataformas que tiveram a preocupação de retratar a verdadeira história e cultura cubana, a saber: o filme Habana Blues, do diretor Benito Zambrano; o documentário "Ya tú sabes Expedición al enigma cubano", de Gabriela Esquivada; e sites oficiais da imprensa cubana.

Logo, constatou-se que, o fato dos estudantes reavaliar e ressignificar seus conceitos para posteriormente selecionar 
materiais criativos e críticos, organizá-los, ressignificá-los e contextuálizá-los de acordo com seus interesses, permitiu estabelecer múltiplos sentidos e relações que ultrapassaram a dimensão individual para se transformar em um contexto de aprendizagem que valorizou a diversidade cultural e o outro. Nesse sentido, os estudantes foram unânimes em afirmar e reconhecer a importância de contribuir com o outro, incentivando a participação do colega, aceitando e incorporando à contribuição do outro.

Nesse contexto, ressalta-se que os diálogos e as interações entre os estudantes não ocorreram somente de forma harmônica, também ocorreram confronto de ideias e de pontos de vista. Ao longo das investigações dos trabalhos na oficina, fomos constatando o potencial dessa forma de conflito de opiniões no sentido de estimularem ainda mais um debate aberto aos vários interesses envolvidos, contribuindo, dessa forma, para o encontro de soluções criativas para os problemas. Logo, esse modo de colaboração estabelecido caminhou para uma prática dialógico-problematizadora, conforme define Freire (2011b) e Bakhtin (2009), em que as trocas de informações e conhecimentos entre pares enfatizam conteúdos pertinentes numa explosão de ideias que problematizam e desafiam todos os integrantes do grupo a produzirem uma obra de arte de alto valor estético e rica em conhecimentos culturais e em produção linguística.

Em outro aspecto, destaca-se a forma como os estudantes conseguiram romper suas visões estereotipas em relação ao país Cuba. Diante dessa experiência, destaca-se os estudos de Byram \& Fleming (2001), Kraviski (2007) e Santos (2002) apontam a importância da promoção de um ensino intercultural atrelado ao ensino de língua estrangeira como forma de eliminar estereótipos culturais e despertar a consciência do estudante para os valores e significados das diferenças culturais. Estes autores defendem a necessidade do estudante passar por um processo de formação intercultural capaz de prepará-lo para interpretar os novos fenômenos culturais, no sentido de produzir conhecimento em relação às outras culturas, desenvolvendo uma visão dialógica da sociedade e tornando-o capaz de aceitar o outro e a si mesmo.
Observamos que os estudantes menos experientes na língua estrangeira e/ou nas artes cênicas foram auxiliados pelos estudantes mais experientes, e num processo de influência mútua, ambos avançaram em seus conhecimentos e nas descobertas de novas formas de aprendizagem. Assim, após a interação dialógica, os saberes e as habilidades do "outro" foram internalizadas pelo "eu", e colocadas em prática, logrando sucesso em situações comunicativas. Trata-se pois de um conhecimento socialmente construído por meio da língua viva.

Sob esta ótica, vale destacar a fala do estudante Pedro, o qual ressaltou que, ao longo dos trabalhos de produção do espetáculo, cada estudante procurou compartilhar com os seus colegas as estratégias que utilizaram para aprender a língua espanhola e posteriormente inseri-la como língua alvo nos materiais cênicos. Pedro também ressaltou que o grupo promoveu reflexões coletivas sobre as tentativas que foram bem sucedidas e as que precisaram de ajustes durante o processo de aprendizagem e construção artística. Nesse sentido, Figueiredo (2006) defende que cada estudante tem o seu próprio modo de aprender a língua estrangeira, de forma que o seu estilo de aprendizagem pode influenciar o uso de estratégias ou técnicas que irão contribuir na aprendizagem do idioma. Nessa perspectiva, o autor aponta que a interação colaborativa apresenta-se como um oportuno e potente recurso para o ensino de línguas, visto que propicia aos alunos oportunidades de trocas de saberes, de experiências, de técnicas e de estratégias de aprendizagem.

Logo, a metodologia colaborativa propiciou contextos de aprendizagem que capacitaram os estudantes e os impulsionou na busca pelas estratégias de aprendizagem mais adequadas para aprender os conteúdos da língua espanhola e das artes cênicas e, assim, compartilhá-los com todos os membros dos grupos criativos, num relação dialógica envolvendo o uso crítico, alteritário e consciente da língua estrangeira.

Para os estudantes líderes dos grupos criativos, Pedro, Érica, Maria, Ana e Robson, a metodologia colaborativa do projeto e os seus professores orientadores contribuíram para "transformar o estudo da cultura cubana em um grande e divertido desafio [...]" (Ana, 
2018); "e esse desafio só foi superado por meio da pesquisa, da colaboração com todos [...]" (Pedro, 2018); "[...] por meio da aceitação do outro, da negociação com o outro" (Maria, 2018); "e também por meio da troca de saberes e experiências e por meio da resolução de problemas" (Robson, 2018). Ou seja, o trabalho colaborativo desempenhado por esses estudantes contribuiu mutuamente na construção do conhecimento, ao passo que cada um dos envolvidos assumiu a responsabilidade pela sua aprendizagem e pela aprendizagem do grupo, num relacionamento dialógico, onde rígidas hierarquias deram lugar a lideranças compartilhadas.

Portanto, a metodologia colaborativa mostrou-se indispensável no ensino de idiomas e de arte, tendo em vista que estamos falando do ensino de linguagens, nesse sentido, o ensino de uma língua viva se faz colaborativo e dialógico por natureza (Bakhtin, 2009), pois toda língua é, simultaneamente, o objeto de conhecimento e o meio de aprendizagem (Figueiredo, 2006). Logo, a metodologia de educação colaborativa somada as estratégias criativas do Projeto Espanglish proporcionaram oportunidades para que os estudantes participassem de interações reais fazendo uso da língua estrangeira.

Vale destacar que essa interação real e dialógica é uma das condições essenciais apontadas nos estudos de Figueiredo (2006), de Lima \& Pinho (2007) e de Lopes (2010), para garantir o sucesso da aprendizagem de uma língua estrangeira. Além disso, evidenciamos que os estudantes produziram influências mútuas por meio de um trabalho em equipe que foi capaz de desenvolver habilidades comunicativas, artísticas e interculturais, além de desenvolver outras competências mais técnicas relacionadas às artes cênicas e as competências e habilidades em aprender uma língua estrangeira, em suas dimensões da leitura, da escrita, da escuta e da fala.

Em pergunta aberta, direcionado aos estudantes e aos professores participantes das oficinas, questionamos quais os benefícios dessa metodologia como recurso potencial em suas práticas de ensinoaprendizagem de idiomas e de arte. Os professores citaram diversos benefícios, a saber: "a experiência favoreceu a construção colaborativa do conhecimento, gerando, por meio da autoria coletiva, uma produção artística em idioma espanhol"; "contribuiu para formar um estudante pesquisador-autor", "potencializou modos de expressar e praticar linguagens" (Professor A, 2018); "potencializa a formação de redes de aprendizagem em que seus membros produzem e ao mesmo tempo validam as informações e conhecimentos", "possibilidade de criação colaborativa de textos e materiais cênicos multidirecionais que dialogaram com múltiplas vozes e canais como imagem, vídeo, áudio e texto, dando mais dinamicidade, atratividade, sustentação e aprofundamento aos conteúdos produzidos" (Professor B, 2018); "supera o modelo de produção individualista para dar vazão à produção coletiva", "potencializa a investigação curiosa dos educandos e a busca ativa por soluções aos problemas apresentados", "favorece uma maneira democrática e flexível de aprendizagem centrada no papel ativo do estudante e no papel mediador do professor" (Professor C, 2018).

Já os estudantes afirmaram que a metodologia proporcionou benefícios para suas aprendizagens, como: "jeito divertido e interessante de aprender e pesquisar" (Vera, 2018); "facilita a interação, a cooperação e o compartilhamento de conteúdo e de conhecimentos" (Ana, 2018); "facilita a criação colaborativa de textos e de produções artísticas onde todos podem atuar como autores e tendo voz e vez para criar, ensinar e aprender" (Flávio, 2018); "possibilita que jovens estudantes produzam conteúdo coletivo e colaborativo para outros jovens estudantes" (Marcos, 2018).

Em relação aos pontos fracos, os professores e os estudantes apontaram algumas dificuldades que surgiram no início do projeto, mas que foram superadas no decorrer da pesquisa, sendo elas: pouca experiência com um trabalho que se constrói de forma coletiva e colaborativa; medo de errar e se expor; sentimento de constrangimento ao participar dos primeiros ensaios artísticos; preocupação com a possível incoerência entre textos, ideias e materiais cênicos produzidos pelos diversos grupos criativos. 
Assim, esse experimento comunicativo potencializou as ações e as atitudes colaborativas dos sujeitos, o desenvolvimento de estratégias e a produção de roteiros para o espetáculo artístico do Projeto Espanglish elaborados de forma livre e espontânea, gerando obras diversificadas, criativas, ricas e interdisciplinares, em diálogo com alguns elementos significativos do seu cotidiano e da cultura estrangeira pesquisada.

\section{considerações finais}

Nesse estudo unimos potencialidades do projeto Espanglish, sob a perspectiva da educação colaborativa aplicada ao ensino de língua estrangeira e de arte. Os estudantes foram desafiados a se conectar com a sua comunidade e com o mundo, a relacionar a língua estrangeira à sua própria língua, a sua própria cultura e arte e aplicá-la ao idioma espanhol em um novo contexto social. Dessa forma, eles desenvolveram competências e produziram conhecimentos novos, que não teriam condições de se desenvolver isoladamente.

Os resultados apontam a potencialidade do Projeto Espanglish e da metodologia colaborativa em possibilitar a troca dialógica de saberes entre estudantes, professores e comunidade. Apresenta, também, algumas possibilidades de inovações nas práticas escolares da educação básica e profissional, através do desenvolvimento de competências técnicas, cognitivas, linguístico-comunicativas e estético-expressivas essenciais à formação escolar.

Constatamos que para promover um ensino-aprendizagem significativo, é de fundamental importância centrar a mediação linguística e pedagógica em ações e perspectivas teóricas que implicam em: um ensino-aprendizagem centrado no dialogismo e na colaboração; focar o papel do docente numa performance alicerçada no diálogoproblematizador e na ação colaborativa; promover um estudo criterioso e rigoroso, centrado na necessidade de conhecer e saber utilizar as ferramentas mais adequadas às metodologias de ensino e aprendizagem colaborativa e dialógica; intensificar a todo instante o diálogo-problematizador em torno dos conteúdos explorados; repensar, rediscutir e compreender permanentemente o conceito de colaboração para que, ao longo de todo o processo, possa embasar as reflexões e práticas de todos os sujeitos envolvidos no processo; conhecer o estudante, compreender e reconhecer seus saberes e experiências, além de perceber as transformações epistemológicas, tecnológicas e sócio-culturais que ocorrem em nossa contemporaneidade.

Tomando como base nossas próprias experiências como professores de língua estrangeira e arte, entendemos que todas essas estratégias devem ser criteriosamente inseridas na essência da base curricular e nas diretrizes dos projetos pedagógicos das instituições de ensino. E, tanto os professores, quanto os estudantes, podem receber muitos benefícios se buscarem o amplo acesso à metodologia colaborativa, e, sobretudo, se buscarem acesso às possibilidades e estratégias de incorporá-las ao cotidiano escolar, por meio de um processo de ensinoaprendizagem concebido à luz da perspectiva dialógica e problematizadora que defendemos e adotamos como base epistemológica para o Projeto Espanglish.

\section{referências}

Aparici, R. \& Acedo, S. (2010). Aprendizagem colaborativa e ensino virtual: uma experiência de universidade à distância. In M. Silva; L. Pesce \& A. Zuin (Orgs.). Educação online: cenário, formação e questões didático-metodológicas. Rio de Janeiro: Wak Ed., 137-156.

Bagetti, S. (2015). Mediação pedagógica no ensino-aprendizagem colaborativo do sistema E-Tec Brasil. Dissertação (Mestrado). Universidade Federal de Santa Maria, Santa Maria, Rio Grande do Sul, Brasil.

Bakhtin, M. (2009). Marxismo e filosofia da linguagem: problemas fundamentais do método sociológico na ciência da linguagem. São Paulo: Hucitec.

Bakhtin, M. (2011). Estética da criação verbal. (6a ed., P. Bezerra, Trad.), São Paulo: Martins Fontes.

Brant, J. (2008). O lugar da educação no confronto entre colaboração e competição. In N. L. Pretto \& S. A. Silveira (Orgs.). Além das redes de colaboração: internet, diversidade cultural e tecnologias do poder. Salvador: Editora EDUFBA. 
Brasil (2013). Diretrizes Curriculares Nacionais Gerais da Educação Básica. Ministério da Educação. Secretária de Educação Básica. Diretoria de Currículos e Educação Integral. Brasília: MEC, SEB, DICEI.

Brasil (2018). Ministério da Educação. Base Nacional Comum Curricular/BNCC: Educação é a Base. Homologada em 14 de dez.

Byram, M. \& Fleming, M. (2001). Perspectivas Interculturales en el aprendizaje de idiomas. Madrid: Cambridge University Press.

Figueiredo, F. J. Q. (2006). A aprendizagem colaborativa de línguas: algumas considerações conceituais e terminológicas. In F. J. Q. Figueiredo (Org.). A aprendizagem colaborativa de línguas. Goiânia: Editora da UFG, 11-45.

Freire, P. (1996). Pedagogia da autonomia: saberes necessários à prática educativa. (40a ed.), Rio de Janeiro: Paz e Terra.

Freire, P. (2011a). Educação como prática para a liberdade. (14a ed.), Rio de Janeiro: Paz e Terra,

Freire, P. (2011b). Pedagogia do oprimido. (50a ed.), Rio de Janeiro: Paz e Terra.

Gil, A. C. (2008). Métodos e técnicas de pesquisa social. (6a ed.), São Paulo: Atlas.

Kraviski, E. R. A. (2007). Estereótipos Culturais: o ensino de espanhol e o uso da variante argentina em sala de aula. Dissertação (Mestrado). Universidade Federal do Paraná, Curitiba, Paraná, Brasil.

Lima, M. \& Pinho, I. C. (2007). A tarefa colaborativa como estímulo à aprendizagem de língua estrangeira. In M. Lima \& R. M. Graça (Orgs.). Ensino e aprendizagem de língua estrangeira: relações de pesquisa Brasil/Canadá. Porto Alegre: Armazém Digital, 87-101.

Morin, E. (2008). Introdução ao pensamento complexo. (5a ed.), Lisboa: Stória Editores.

Lopes, D. V. (2010). Grupos de aprendizagem cooperativa e o ensino da escrita em língua inglesa. In V. Moura, M. C. Damianovic \& V. Leal (Orgs.). O ensino de línguas: concepções e práticas universitárias. Recife: Ed. UFPE, 47-61.
Pretto, N. L. (2013). Reflexões: ativismo, redes sociais e educação. Salvador: EDUFBA.

Santos, E. M. (2004). Abordagem Comunicativa Intercultural: uma proposta para ensinar e aprender língua no diálogo de culturas. Tese (Doutorado). Universidade Estadual de Campinas, Campinas, São Paulo, Brasil.

Santos, H. S. (2002). O papel de estereótipos e preconceitos na aprendizagem de línguas estrangeiras. In Congreso Brasileño de Hispanistas. São Paulo: Anales da Associação Brasileira de Hispanistas. recebido em 15/07/2020 aceito em 10/09/2020 